$\mathbb{T}$ periodica polytechnica

Mechanical Engineering $52 / 2$ (2008) 107 112

doi: 10.3311/pp.me.2008-2.11 web: http://www.pp.bme.hu/me

(c) Periodica Polytechnica 2008

RESEARCH ARTICLE

\section{Investigation of the load transmission in the toothing of a flat wheel harmonic gear drive}

\author{
Róbert Krisch / István Házkötő
}

Received 2008-01-18

\begin{abstract}
The function principle of the flat wheel harmonic gear drive is similar to the basic principle of the classical harmonic drives. The flexible and the rigid gear of the drive are coaxial flat wheels. The rotating wave generator deforms periodically and elastically different portions of an annular face gear on the flexible member in axial direction into engagement with teeth on an annular face gear on the rigid member. The numbers of teeth of the face gears are different. An analytical method is introduced, that investigates backlash conditions of flat-wheel harmonic drives. The tooth flanks were approximated by planes. The numbers of the connected teeth taking part in the loadtransmission and the tangential component of the acting force on them in the range of tooth engagement are dependent on backlash. Finite element investigations were launched at different levels of torques even in case of preloaded flexible gear.
\end{abstract}

\section{Keywords}

Harmonic drive $\cdot$ gear $\cdot$ backlash $\cdot$ tooth load $\cdot$ tooth deformation

\section{Róbert Krisch}

István Házkötő

Department of Product- and Machine Design, BME, H-1111 Budapest, Múegyetem rkp. 3, Hungary

\section{Introduction}

For the dimensioning and endurance determination of a flat wheel harmonic drive it is necessary to know the amplitude of force acting on teeth and the number of tooth-pairs taking part in the load transmission of the drive in case of a prescribed loading torque. One possible way to determine this force is the finite element analysis (FEA), the other one is an analytical approximation. This paper reports a method for backlash calculation and investigates load transmission in the toothing in case of preloaded flexible gear, which is used for reducing clearance of the gear.

\section{Description and operation of a flat wheel harmonic gear drive}

As for the function principle of the flat wheel harmonic drive (Fig. 1), it is similar to the basic principle of the classical harmonic drives; it could be regarded as a special variety of them. The flexible and the rigid gear of the drive are coaxial flat wheels. The cam-type wave generator $(\mathrm{G})$ consisting of a flexible axial bearing and a disc with cams, deforms the flexible gear (1) in axial direction periodically and elastically, the toothing of which comes into mesh with the toothing of the rigid gear (2).

\section{SOLID GEAR (2) FLEXIBLE GEAR (1) WAVE GENERATOR (G)}
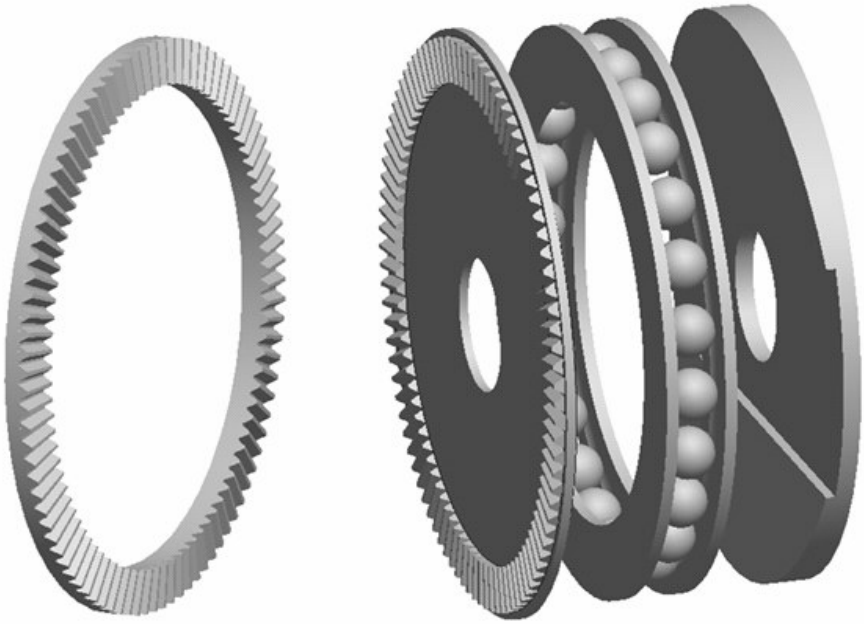

Fig. 1. Basic parts of flat-wheel harmonic gear drive and their photos 
Fig. 22 shows the schematic representation of the engagement, where $\phi$ is the polar angle from the top of the deformation wave made of the wave generator, $\phi=0^{\circ}$ means the symmetry plane of the deformation wave. Since the flexible and rigid gears have a different number of teeth, there will be a relative rotational motion between the flexible and the solid gear.

The kinematic ratio of the investigated harmonic drive, in case of rigid gear is fixed, flexible wheel connects to the output shaft, wave generator connects to the input shaft, can be calculated as the following:

$$
i_{12}=\frac{z_{1}}{z_{1}-z_{2}}
$$

where $z_{1}$ describes the number of teeth of the flexible wheel, $z_{2}$ describes the number of teeth on the rigid wheel.
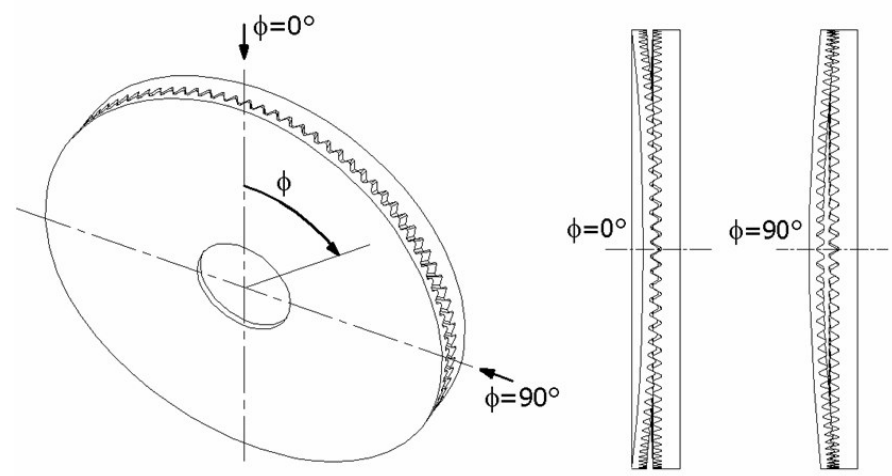

Fig. 2. Schematic representation of the engagement in flat-wheel harmonic gear

\section{Applied coordinate systems for the backlash calcu- lation}

Fig. 3 shows the meshing of teething in radial and tangential direction; dashed line indicates the deformed shape. Coordinate system $\left[\mathrm{x}_{2}, \mathrm{y}_{2}, \mathrm{z}_{2}\right]$ is fixed to the rigid wheel; its centre point $\left(\mathrm{O}_{2}\right)$ is on the outer diameter $\left(d_{k}\right)$ of the pitch cone in the symmetry plane of the investigated tooth groove; $x_{2}$ is the axis of tangential; $y_{2}$ is the axis of radial and $z_{2}$ is the axis of axial direction. Coordinate system $\left[\mathrm{x}_{1}, \mathrm{y}_{1}, \mathrm{z}_{1}\right]$ is fixed to the flexible wheel; its centre point $\left(\mathrm{O}_{1}\right)$ is on the outer diameter $\left(\mathrm{d}_{k}\right)$ of the neutral plane of the wheel in the symmetry plane of the investigated tooth; $x_{1}$ is the axis of tangential; $y_{1}$ is the axis of radial and $\mathrm{z}_{1}$ is the axis of axial direction (hereafter index ' 1 ' means the flexible, '2' the rigid wheel).

\section{Coordinates of the investigated points of the toothing}

Backlashes were determined by calculation of the distances between the addendum points of one gear and the tooth flank of the other gear. Coordinates of the addendum and dedendum points of the investigated tooth of the rigid gear in coordinate system $\left[\mathrm{x}_{2}, \mathrm{y}_{2}, \mathrm{z}_{2}\right]$ on the outer and inner diameter of the toothing (Figure 3/b and 3/c) (hereafter superscript "2" means the rigid gear superscript " 1 " the flexible gear coordinate system):

$$
\left.\begin{array}{c}
P_{a 2 x}^{2}=\frac{-e_{2}}{2}-h_{a 2} \cdot \tan \alpha_{2} \\
P_{a 2 y}^{2}=0 \\
P_{a 2 z}^{2}=\frac{-h_{a 2}}{\cos \beta_{2}}
\end{array}\right\}
$$

Coordinates of the points in the inner diameter (superscript "b" means the inner diameter):

$$
\left.\begin{array}{l}
P_{a 2 b x}^{2}=\frac{-e_{2}\left(d_{b} / d_{k}\right)}{2}-h_{a 2} \cdot\left(d_{b} / d_{k}\right) \cdot \tan \alpha_{2} \\
P_{a 2 b y}^{2}=\frac{\left(d_{b}-d_{k}\right)}{2} \\
P_{a 2 b z}^{2}=\tan \beta_{2} \cdot \frac{\left(d_{b}-d_{k}\right)}{2}-\frac{h_{a 2}\left(d_{b} / d_{k}\right)}{\cos \beta_{2}}
\end{array}\right\}
$$

$$
\begin{aligned}
P_{f 2 b x}^{2} & =\frac{-e_{2}\left(d_{b} / d_{k}\right)}{2}+h_{f 2} \cdot\left(d_{b} / d_{k}\right) \cdot \tan \alpha_{2} \\
P_{f 2 b y}^{2} & =\frac{\left(d_{b}-d_{k}\right)}{2}-\sin \beta_{2}\left(h_{a 2}+h_{f 2}-c_{2}\right) \cdot\left(d_{b} / d_{k}\right) \\
P_{f 2 b z}^{2} & =\tan \beta_{2} \cdot \frac{\left(d_{b}-d_{k}\right)}{2} \\
& +\cos \beta_{2}\left(h_{a 2}+h_{f 2}-c_{2}\right) \cdot\left(d_{b} / d_{k}\right)-\frac{h_{a 2}\left(d_{b} / d_{k}\right)}{\cos \beta_{2}}
\end{aligned}
$$

Coordinates of the points of the investigated tooth of the flexible gear in coordinate system $\left[\mathrm{x}_{1}, \mathrm{y}_{1}, \mathrm{z}_{1}\right]$ on the outer and inner diameter of the toothing in case of the flexible gear is not deformed by the wave generator (Fig. 3/b):

$$
\left.\begin{array}{rl}
P_{a 10 x}^{1} & =\frac{-s_{1}}{2}+h_{a 1} \cdot \tan \alpha_{1} \\
P_{a 10 y}^{1} & =0 \\
P_{a 10 z}^{1} & =\frac{v}{2}+h_{a 1}+h_{f 1}
\end{array}\right\}
$$

On the inner diameter

$$
\left.\begin{array}{rl}
P_{a 10 b x}^{1} & =\left(\frac{-s_{1}}{2}+h_{a 1} \cdot \tan \alpha_{1}\right) \cdot d_{b} / d_{k} \\
P_{a 10 b y}^{1} & =\frac{d_{b}-d_{k}}{2} \\
P_{a 10 b z}^{1} & =\frac{v}{2}+h_{f 1}+h_{a 1} \cdot d_{b} / d_{k}
\end{array}\right\}
$$

Coordinates of the investigated points of the flexible gear tooth in deformed state of the flexible gear against $\phi$ in coordinate 

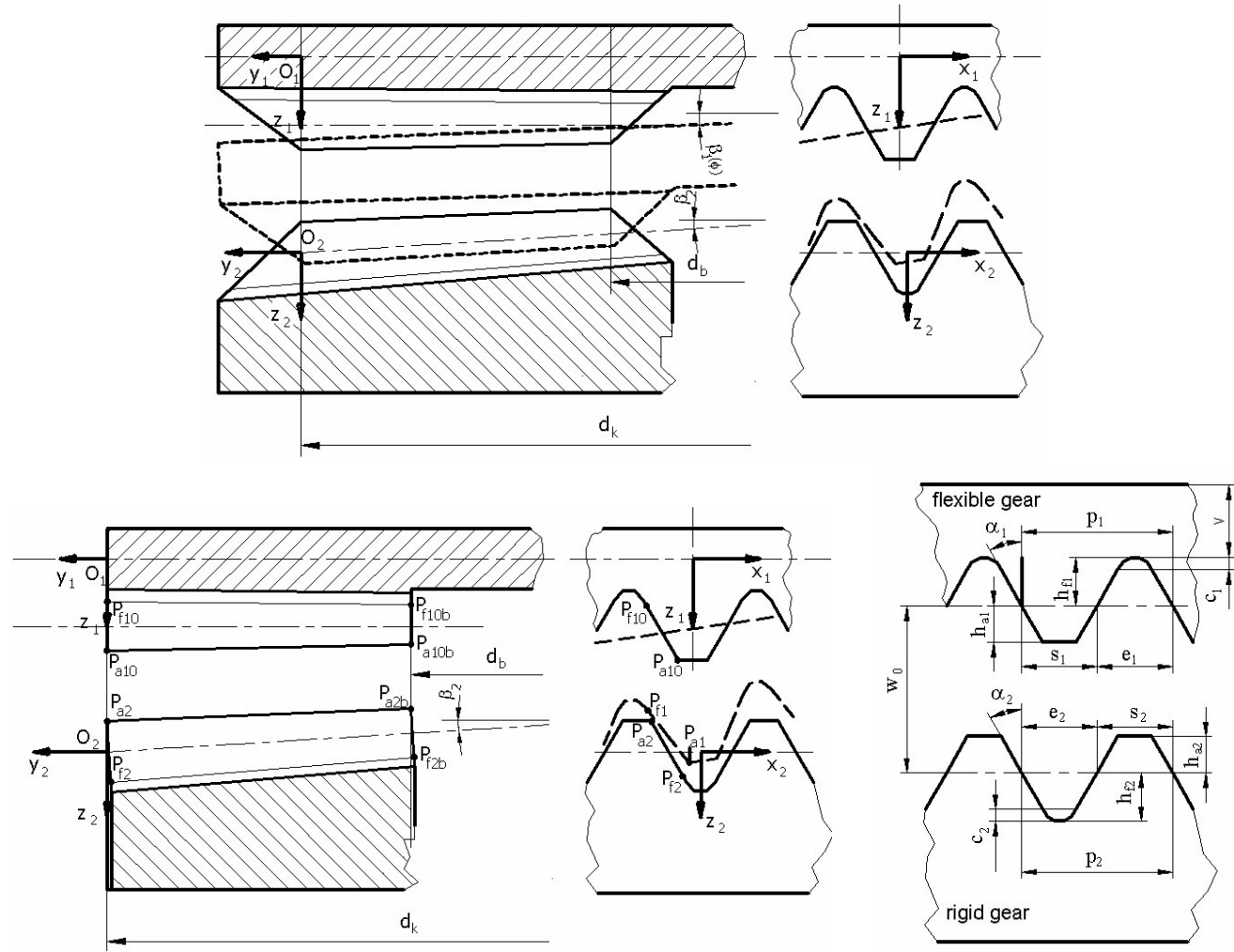

Fig. 3. Applied coordinate systems and the investigated points

system $\left[\mathrm{x}_{1}, \mathrm{y}_{1}, \mathrm{z}_{1}\right]$ :

$\left[\begin{array}{c}\mathrm{P}_{\mathrm{a} 1 \mathrm{x}}^{1}(\varphi) \\ \mathrm{P}_{\mathrm{a} 1 \mathrm{y}}^{1}(\varphi) \\ \mathrm{P}_{\mathrm{a} 1 \mathrm{z}}^{1}(\varphi)\end{array}\right]=$

$\left[\begin{array}{l}u(\varphi) \\ v(\varphi) \\ w(\varphi)\end{array}\right]+\left[\begin{array}{lll}\cos \left(R_{y}(\varphi)\right) & 0 & \sin \left(R_{y}(\varphi)\right) \\ 0 & 1 & 0 \\ -\sin \left(R_{y}(\varphi)\right) & 0 & \cos \left(R_{y}(\varphi)\right)\end{array}\right]$

$\cdot\left[\begin{array}{lll}1 & 0 & 0 \\ 0 & \cos \left(\beta_{1}(\varphi)\right) & -\sin \left(\beta_{1}(\varphi)\right) \\ 0 & \sin \left(\beta_{1}(\varphi)\right) & \cos \left(\beta_{1}(\varphi)\right)\end{array}\right] \cdot\left[\begin{array}{l}\mathrm{P}_{\mathrm{a} 10 \mathrm{x}}^{1} \\ \mathrm{P}_{\mathrm{a} 10 \mathrm{y}}^{1} \\ \mathrm{P}_{\mathrm{a} 10 \mathrm{z}}^{1}\end{array}\right]\left[\begin{array}{l}\mathrm{P}_{\mathrm{a} 1 \mathrm{x}}^{1}(\varphi) \\ \mathrm{P}_{\mathrm{a} 1 \mathrm{y}}^{1}(\varphi) \\ \mathrm{P}_{\mathrm{a} 1 \mathrm{z}}^{1}(\varphi)\end{array}\right]$

$=\left[\begin{array}{l}u(\varphi)+\cos \left(R_{y}(\varphi)\right) \cdot P_{a 10 x}^{1}+\sin \left(R_{y}(\varphi)\right) \cdot \cos \left(\beta_{1}(\varphi)\right) \cdot P_{a 10 z}^{1} \\ v(\varphi)-\sin \left(\beta_{1}(\varphi)\right) \cdot P_{a 10 z}^{1} \\ w(\varphi)-\sin \left(R_{y}(\varphi)\right) \cdot P_{a 10 x}^{1}+\cos \left(R_{y}(\varphi)\right) \cdot \cos \left(\beta_{1}(\varphi)\right) \cdot P_{a 10 z}^{1}\end{array}\right]$

In the relation:

$w(\varphi)=w_{0}-d / 2 \cdot(1-\cos \varphi) \operatorname{tg} \beta-$ deformation of the flexible gear against $\phi$ gn the investigated diameter $-\mathrm{d}$ means $\mathrm{d}_{k}$ or $\mathrm{d}_{b}$ - of the toothing in case of the working surfaces of the cam of the wave generator are planes that shows Fig. 4

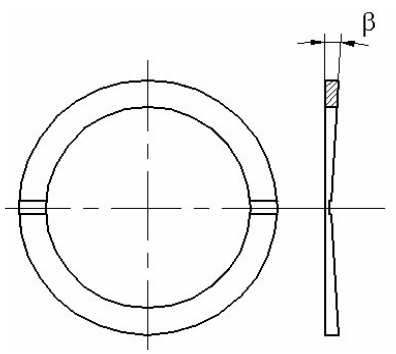

Fig. 4. Working surface of the cam type wave generator

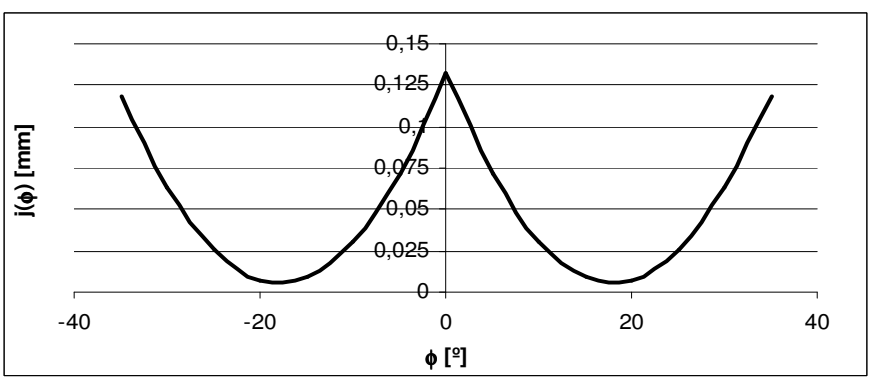

Fig. 5. Backlash in tooth-pairs against $\phi$

$u(\varphi) \quad$ - displacement of the investigated point in tangential direction based on the supposed unstretchability of the flexible gear plate against $\phi$ gnd the investigated diameter of the toothing

$v(\varphi) \quad$ - displacement of the investigated point in radial direction based on the supposed unstretchability of the flexible gear plate against $\phi$ gnd the investigated diameter of the toothing $R_{y}(\varphi)=\operatorname{arctg}\left(-\operatorname{tg} \beta_{g} \cdot \sin \phi\right) \quad$ - rotation of the tooth of the flexible gear around 'y' axis caused by the deformation against $\phi$

$\beta_{1}(\varphi)=\beta_{g} \cdot \cos (\varphi) \quad-$ rotation of the tooth of the flexible gear around ' $x$ ' axis against $\phi$ 
Matrix of transformation between the coordinate systems:

$$
\left[\begin{array}{l}
\mathrm{T}_{\mathrm{x}}^{1 \rightarrow 2}(d, \varphi) \\
\mathrm{T}_{\mathrm{y}}^{1 \rightarrow 2}(d, \varphi) \\
\mathrm{T}_{\mathrm{z}}^{1 \rightarrow 2}(d, \varphi)
\end{array}\right]=\left[\begin{array}{l}
-\varphi \cdot \frac{d}{2} \cdot \frac{\left(z_{1}-z_{2}\right)}{z_{2}} \\
0 \\
-w_{0}-\left(\frac{v}{2}+h_{a 1}+h_{f 1}\right)+h_{f 2}-j_{a x}
\end{array}\right]
$$

Coordinates of the investigated points of the flexible gear tooth in deformed state of the flexible gear against $\phi$ in coordinate system $\left[\mathrm{x}_{2}, \mathrm{y}_{2}, \mathrm{z}_{2}\right]$ :

$$
\begin{aligned}
& {\left[\begin{array}{l}
\mathrm{P}_{\mathrm{a} 1 \mathrm{x}}^{2}(\varphi) \\
\mathrm{P}_{\mathrm{a} 1 \mathrm{y}}^{2}(\varphi) \\
\mathrm{P}_{\mathrm{a} 1 \mathrm{z}}^{2}(\varphi)
\end{array}\right]} \\
& =\left[\begin{array}{l}
u(\varphi)+\cos \left(R_{y}(\varphi)\right) \cdot P_{a 10 x}^{1}+\sin \left(R_{y}(\varphi)\right) \cdot \cos \left(\beta_{1}(\varphi)\right) \cdot P_{a 10 z}^{1}-\varphi \cdot \frac{d}{2} \cdot\left(\frac{z_{1}-z_{2}}{z_{2}}\right) \\
v(\varphi)-\sin \left(\beta_{1}(\varphi)\right) \cdot P_{a 10 z}^{1} \\
w(\varphi)-\sin \left(R_{y}(\varphi)\right) \cdot P_{a 10 x}^{1}+\cos \left(R_{y}(\varphi)\right) \cdot \cos \left(\beta_{1}(\varphi)\right) \cdot P_{a 10 z}^{1}-w_{0}-\left(\frac{v}{2}+h_{a 1}+h_{f 1}+c_{1}\right)+h_{f 2}-j_{a x}
\end{array}\right]
\end{aligned}
$$

On the inner diameter:

$$
\begin{aligned}
& {\left[\begin{array}{l}
\mathrm{P}_{\mathrm{a} 1 \mathrm{bx}}^{2}(\varphi) \\
\mathrm{P}_{\mathrm{a} 1 \mathrm{by}}^{2}(\varphi) \\
\mathrm{P}_{\mathrm{a} 1 \mathrm{bz}}^{2}(\varphi)
\end{array}\right]} \\
& =\left[\begin{array}{c}
u_{b}(\varphi)+\cos \left(R_{y}(\varphi)\right) \cdot P_{a 10 b x}^{1}+\sin \left(R_{y}(\varphi)\right) \cdot \cos \left(\beta_{1}(\varphi)\right) \cdot P_{a 10 b z}^{1}-\varphi \cdot \frac{d_{b}}{2} \cdot\left(\frac{z_{1}-z_{2}}{z_{2}}\right) \\
P_{a 10 b y}^{1}+v_{b}(\varphi)-\sin \left(\beta_{1}(\varphi)\right) \cdot P_{a 10 b z}^{1} \\
w_{b}(\varphi)-\sin \left(R_{y}(\varphi)\right) \cdot P_{a 10 b x}^{1}+\cos \left(R_{y}(\varphi)\right) \cdot \cos \left(\beta_{1}(\varphi)\right) \cdot P_{a 10 b z}^{1}-w_{0}-\left(\frac{v}{2}+h_{a 1}+h_{f 1}\right)+h_{f 2}-c_{2}-j_{a x}
\end{array}\right]
\end{aligned}
$$

where:

$w_{b}(\varphi)=w_{0}-\tan \beta_{g} \cdot \frac{\left(d_{k}-d_{b}\right)}{2}-d_{b} / 2 \cdot(1-\cos \varphi) \operatorname{tg} \beta_{g} \quad-$ deformation of the flexible gear against $\phi$ gnd on the inner diameter of the toothing. Normal vector of the solid wheel tooth flank:
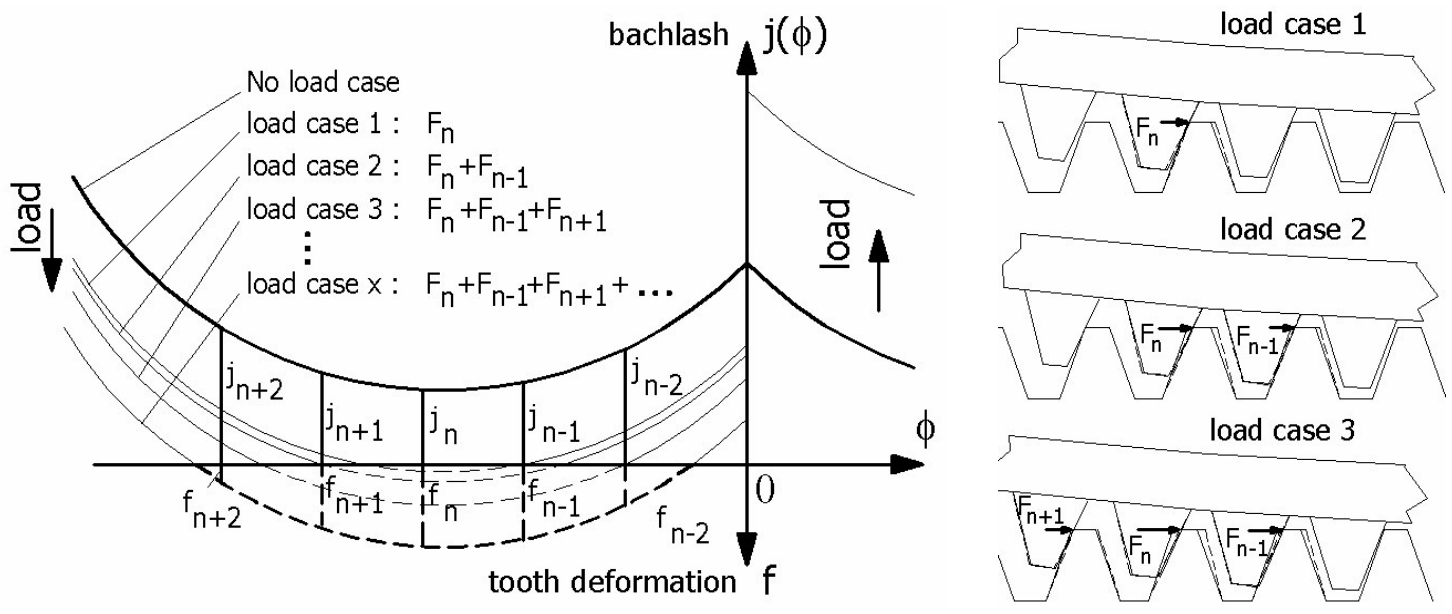

Fig. 6. Backlash and tooth deformation in different load cases

$$
\underline{n}_{2}=\left(\underline{p}_{a 2 b}-\underline{p}_{a 2}\right) \times\left(\underline{p}_{f 2}-\underline{p}_{a 2}\right)
$$

Distance between outer addendum edge endpoint of flexible gear $\left(\mathrm{P}_{a 1}\right)$ and tooth flank plane of the solid wheel:

$$
j_{12}(\phi)=\frac{\underline{n}_{2 x} \cdot \underline{p}_{a 1 x}^{2}(\phi)+\underline{n}_{2 y} \cdot \underline{p}_{a 1 y}^{2}(\phi)+\underline{n}_{2 z} \cdot \underline{p}_{a 1 z}^{2}(\phi)-\left(\underline{n}_{2 x} \cdot \underline{p}_{a 2 x}^{2}+\underline{n}_{2 y} \cdot \underline{p}_{a 2 y}^{2}+\underline{n}_{2 z} \cdot \underline{p}_{a 2 z}^{2}\right)}{\left|\underline{n}_{2}\right|}
$$


We can use similar expression for the inner diameter $\left(\mathrm{j}_{12 b}(\phi)\right)$ and for calculating the distance between addendum edge endpoint of the solid gear and tooth flank of the flexible gear $\left(\mathrm{j}_{21}(\phi)\right)$ on the inner and outer diameter. Backlash in tangential direction can be determined by the following expression:

$$
j(\phi)=\min \left(j_{12}(\phi), j_{21}(\phi), j_{12 b}^{*}(\phi), j_{21 b}^{*}(\phi)\right) / \cos \alpha
$$

where $j_{12 b}^{*}(\phi)$ and $j_{21 b}^{*}(\phi)$ are backlashes on the inner diameter transformed onto the outer diameter, $\alpha=\alpha_{1}+\mathrm{R}_{y}(\phi)$ if $\mathrm{j}_{21}(\phi)>$ $\mathrm{j}_{12}(\phi)$ or $\alpha=\alpha_{2}$ if $\mathrm{j}_{21}(\phi)<\mathrm{j}_{12}(\phi)$.

\section{Load transmission in the toothing}

Fig. 5 shows the distribution of backlash between the teeth in an examined drive against $\phi \mathrm{g}$ in no-load-state of the drive.

Main sizes and toothing parameters of the examined drive were determined according to non-fictional recommendations [2]: $\mathrm{d}_{k}=190 \mathrm{~mm}-$ outer diameter of toothing, $\mathrm{d}_{b}=160 \mathrm{~mm}-$ inner diameter of toothing, $\mathrm{v}=1.5 \mathrm{~mm}$ - thickness of flexible wheel, $\mathrm{w}_{0}=3 \mathrm{~mm}$ - deformation. Number of teeth of the flexible wheel: $\mathrm{z}_{1}=190$, that of the rigid wheel $\mathrm{z}_{2}=188$, tooth profile parameters at the outer diameter: addendum heights: $\mathrm{h}_{a 1}=$ $\mathrm{h}_{a 2}=0.75 \mathrm{~mm}$; dedendum heights: $\mathrm{h}_{f 1}=\mathrm{h}_{f 2}=0.75 \mathrm{~mm}$; clearance: $c_{1}=c_{2}=0.25 \mathrm{~mm}$, profile angles: $\alpha_{\mathrm{x}} \mathrm{g}, \mathrm{g} \alpha_{\mathrm{y}}=30^{\circ}$, thickness at pitch line: $s_{1}, s_{2}$ are halves of pitch. Cam angle of the wave generator: $\beta \mathrm{g}=\mathrm{g} 3^{\circ}$, angle of toothing of solid wheel: $\beta_{\mathrm{y}} \mathrm{g}=\mathrm{g} 3^{\circ}, \mathrm{g}_{a x}=0.25 \mathrm{~mm}$ - axial clearance between the toothings at $\phi=0^{\circ}$.

Results of backlash examinations showed, that the minimumbacklash appears in areas $-25^{\circ}<\phi \mathrm{g}<-15^{\circ}$ and $15^{\circ}<\phi \mathrm{g}<$ $25^{\circ}$.

Test bench measurements of an experimental drive [3] indicated, that similarly to classical harmonic gear boxes $[4,5,6]$ increasing loading torque causes increasing number of teeth taking part in load transmission. It was indicated moreover, that teeth taking part in load transmission are in the $-\phi$ area.

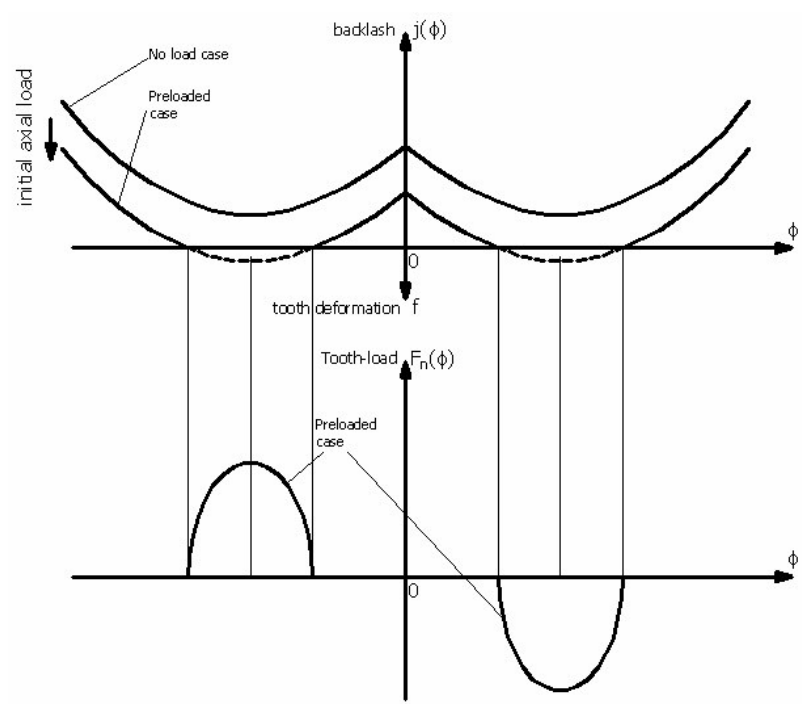

Fig. 7. Backlash and tooth load in case of preloaded flexible gear without loading torque

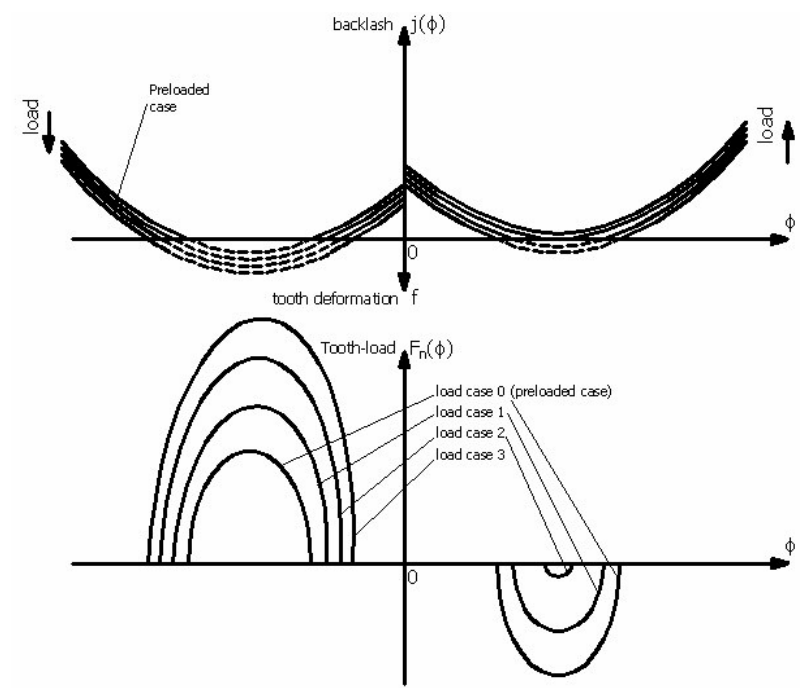

Fig. 8. Backlash and tooth load in case of preloaded flexible gear and loading torque

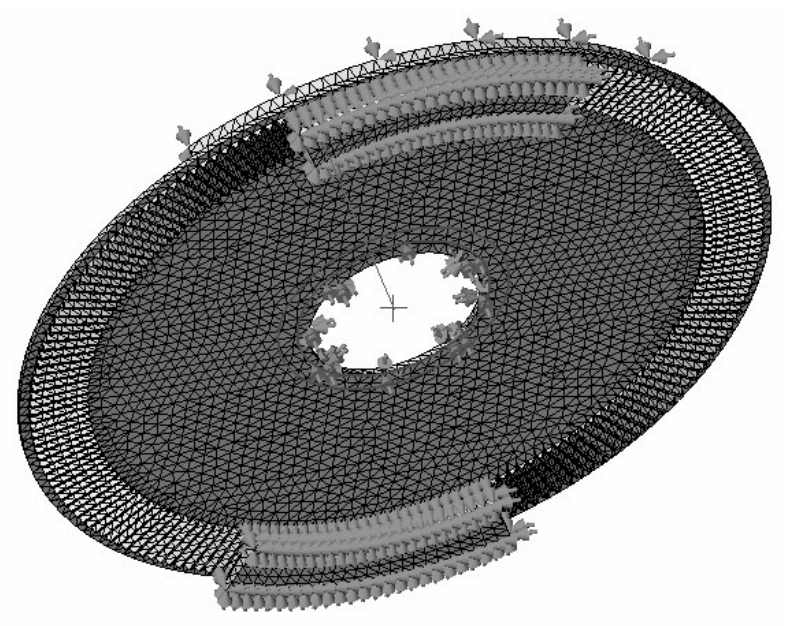

Fig. 9. FEA model of the flat wheel harmonic drive

Fig. 6 shows the load-transmission process in the gear. Continuous thick lines show backlash distribution against $\phi$ gin no-load state of the drive, where minimum of backlash appears at $-\mathrm{g} \phi_{n}$ in the $\mathrm{n}$-th pair of teeth from the top of the deformation wave. Backlash and its location can be influenced by changing tooth parameters [1]. In case of a given backlash-curve backlashes of pairs of teeth in the area of $\phi_{n}$ can be ranged into increasing order, for example:

$$
j_{n}<j_{n-1}<j_{n+1}<j_{n-2}<\ldots
$$

In case of loading torque acting the output shaft of the drive, backlash will decrease in the $-\mathrm{g} \phi$ garea and increase in $+\phi$ area. In Fig. 6 thin lines show different load cases. In that range, where backlash curves are below the horizontal axis, so backlash would be negative, teeth in engagement deform each other in tangential direction. Dashed lines show the common deformation (f) of the tooth pairs.

In load case 1 backlash of the minimum-backlash tooth pair $n$ $\left(\mathrm{j}_{n}\right)$ becomes zero and then teeth of this tooth pair deform each other. Increasing the loading torque, if the common deformation of the teeth of the tooth-pair $n$ comes at $\Delta \mathrm{j}_{1}=\mathrm{j}_{n-1}-\mathrm{j}_{n}$, the next 

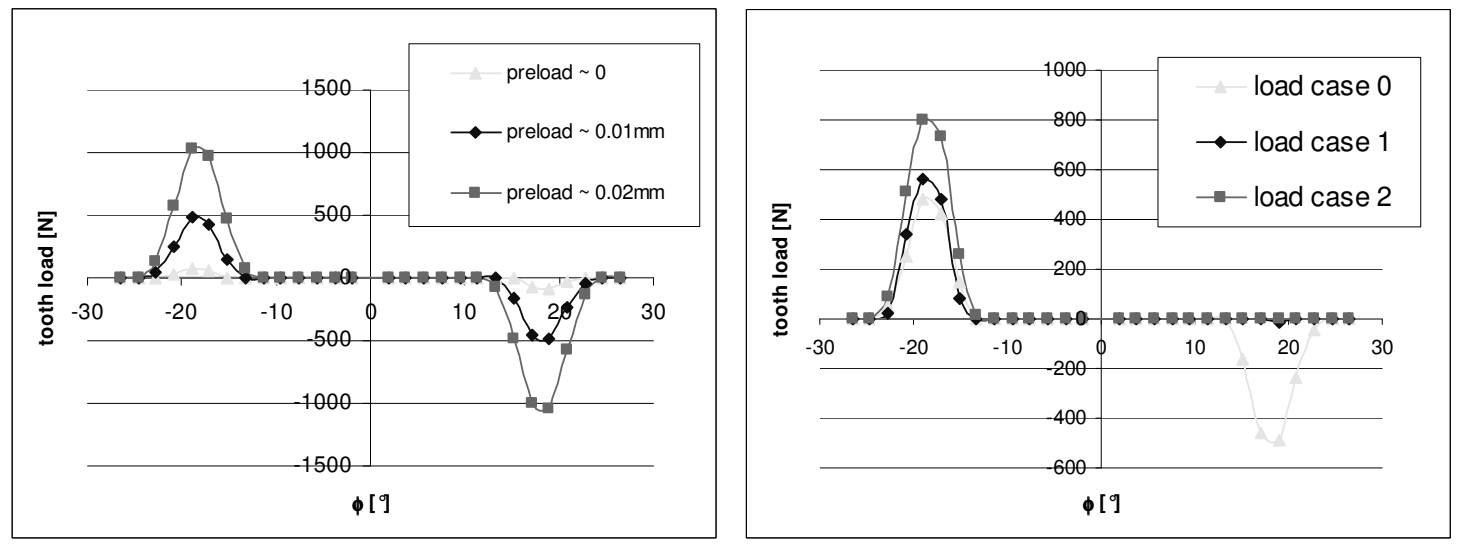

Fig. 10. Distribution of the tangential force on teeth against $\phi$ calculated with FEA

pair of tooth comes into load transmission, in the case above tooth-pair $n-1$. In load case 2 not only the teeth of tooth-pair $n$, but teeth of tooth-pair $n-1$ deform each other. If the deformation in load case 2 reaches $\Delta \mathrm{j}_{2}=\mathrm{j}_{n+1}-\mathrm{j}_{n-1}$, tooth-pair $n+1$ comes into load-transmission (load case 3 ). Pairs of teeth coming into load-transmission go on till the relation below the sum of the tangential force acting on tooth-pairs in both deformation areas comes true:

$$
\sum_{i=1 . . x} F_{i}=\frac{T}{2 d}
$$

where $T$ is the loading torque acting on the output shaft of the drive, $d$ is the outer or inner diameter of the toothing, depending on the place $\mathrm{F}_{i}$ is acting.

\section{The preloaded state of the gear}

For reducing clearance of the gear, the flexible gear can be preloaded by the wave generator in axial direction. In this case backlash will be zero and the teeth will deform each other and initial load will appear on both sides of the deformation wave. Fig. 7 shows the case of axial preload without any loading torque acting on the output shaft.

In case of loading torque acts on the output shaft of the drive it is supposed that rotation of the flexible gear will decrease backlash in the $-\phi$ area, that means tooth load will increase here. On the other side of the deformation wave $(+\phi$ area) backlash will increase and tooth load will decrease (Fig. 8).

\section{Analyzing of the distribution of tangential force on tooth-pairs with FEA}

Amplitude of tangential forces on the teeth of the gear and force distribution in the load-transmission area was analyzed with FEA, Fig. 9 shows the finite element model of the basic parts of the drive.

The assembly contains a whole model of the flexible wheel, because in case of loading there are no symmetry conditions. On the inner border of the annular-shaped plate fix constraint and prescribed rotation was applied. The flexible axial bearing of the wave generator was eliminated, the working surfaces of the cam of the wave generator was modelized in the range of the teeth are in mesh. Prescribed displacement constraint in axial direction was located on these surfaces of wave generator that deflect the flexible wheel in meshing area. Toothing of the rigid wheel was shaped only in the load transmission area; teeth were fixed below their root separated from each other. Between touching faces gap elements were placed and element size was refined. Loading torque was generated by prescribed rotation of the inner border of the flexible wheel, results were the reaction force amplitudes on teeth taking part in load transmission. Analyzes were launched with large displacement calculation method.

\section{FEA results}

Fig. 10 shows the distribution of the tangential force of the teeth against $\phi$ calculated with FEA and analytical method, in case of two different preloads and loading torque for the toothing and geometric parameters described above.

\section{Concluding remarks}

An approximating analytical method was introduced for calculating backlash in the toothing of a flat wheel harmonic gear drive. Tooth load was also analyzed with FEA in case of preloaded flexible gear.

\section{References}

1 Krisch R, Investigation the toothing condition of a flat wheel harmonic gear drive, GEP 57 (2006), no. 8-9, 96-100.

2 Szavinüh A G, Gurjanov M Ja, Szavinüh V M, Parametricseszkij rjad torcovüh volnovüh reduktorov, Vesztnyik Masinosztroenija (1986), no. 1, 79.

3 Krisch R, Hazkötö I, Investigation the toothing condition of a flat wheel harmonic gear drive, GEP 56 (2005), no. 11-12, 110-113.

4 Peter J, Results of research work on flexible gear drives I., $5^{\text {th }}$ International Meeting Of The Carpathian Region Specialists In The Field Of Gears, Nagybanya, 2004, pp. 251-256.

5 , Results of research work on flexible gear drives II, $5^{\text {th }}$ International Meeting Of The Carpathian Region Specialists In The Field Of Gears, Nagybanya, 2004, pp. 257-262.

6 Paetzold K, Die Auslegung von Wellgetrieben aus Kunststoff am Beispiel des WAVE DRIVE-Getriebes Fortsritt-Berichte VDI, 2003. 